\title{
Eficacia del habeas corpus para liberar a una chimpancé (Cecilia). Comentario a la Sentencia de 3 de noviembre de 2016 del Tercer Juzgado de Garantías del Estado de Mendoza (Argentina) ${ }^{1}$
}

\author{
Francisco Capacete González ${ }^{2}$
}

El 3 de noviembre de 2016, el Tercer Juzgado de Garantías del Estado argentino de Mendoza, ha dictado Sentencia concediendo el habeas corpus en favor de la chimpancé Cecilia. Se trata de un fallo histórico y de especial trascendencia en el reconocimiento de los derechos de los animales y de estos como sujetos de derecho. El fallo dice así:

I.- Haber lugar a la acción de HABEAS CORPUS interpuesta por el Dr. Pablo Buompadre, Presidente de la Asociación de Funcionarios y Abogados por los Derechos de los Animales -A.F.A.D.A., con el patrocinio letrado del Dr. Santiago Rauek.

II.- Declarar a la chimpancé Cecilia, actualmente alojada en el zoológico de la Provincia de Mendoza, sujeto de derecho no humano.

III.- Disponer el traslado del chimpancé Cecilia al Santuario de Sorocaba, ubicado en la República del Brasil el que deberá efectuarse antes del inicio del otoño, conforme lo acordado por las partes.

No es la primera vez que la justicia argentina falla a favor de un animal. Recordemos que la Cámara Federal de Casación Penal ya concedió el habeas corpus para la orangutana Sandra ${ }^{3}$. Pero, a diferencia de la anterior sentencia, la que comentamos ahora, motiva y detalla su decisión.

\footnotetext{
${ }^{1}$ http://www.derechoanimal.info/bbdd/Documentos/2189.pdf

${ }^{2}$ Abogado ejerciente especialista en Derecho Animal. Licenciado por la Facultad de Derecho de Illes Balears. Master en Derecho Animal y Sociedad por la UAB (2a ed. online). Representante en Baleares del Proyecto Gran Simio. Asesor de la plataforma de protección animal BALDEA. Ha colaborado en la modificación de la Ley de Protección Animal de Illes Balears para la prohibición de las corridas de toros y en la redacción del borrador del Reglamento del Centro de Protección Animal de Ibiza. Articulista en Diario de Mallorca y la revista Esfinge. Filósofo.

${ }^{3}$ http://www.derechoanimal.info/images/pdf/GFB-Habeas-Corpus-Sandra.pdf
} 
El presentante ha alegado en su petición que desde su alojamiento en el zoo de esta chimpancé, hace más de treinta años, nada se hizo desde ese establecimiento y sus autoridades a favor de su bienestar. La han tenido esclavizada, privada de libertad de modo arbitrario e ilegal, sin ninguna otra finalidad que la de ser exhibida al público como objeto circense. Y que esta situación constituye una trasgresión a la Ley de malos tratos y actos de crueldad a los animales (Ley. Nac. 14346) y a la Ley de Conservación de la Fauna Silvestre (Ley Nac. 22.421) actualmente vigentes en Argentina.

El Fiscal de Estado, por su parte, se ha opuesto a la petición de habeas corpus alegando que no se dan los presupuestos básicos de esta acción porque la chimpancé no es una persona humana y su confinamiento no ha sido ilegal.

La magistrada ha entendido que el caso planteado involucra la protección de un bien o valor colectivo, de modo que debía ir a la cuestión de fondo y no acoger la excepción de falta de legitimidad que el Fiscal había planteado. La Constitución Nacional argentina (art. 43) consagra la acción de amparo colectivo que otorga legitimidad a cualquier persona o colectividad para pedir antes los Tribunales la defensa de aquellos bienes o valores. Estos son, entre otros, el medio ambiente, el patrimonio natural, los valores culturales y la calidad de vida social. La situación de hecho denunciada hacía imperativo el dictado de una resolución judicial que protegiera el valor colectivo en juego.

La chimpancé Cecilia, argumenta la magistrada, pertenece al patrimonio ambiental. "El derecho a la preservación del patrimonio natural y cultural y el derecho a la calidad de vida forman parte del "derecho al ambiente" (Art. 41 CN), constituyen "derechos de incidencia colectiva" y están esencialmente conectados con el interés general de la sociedad".

Se pregunta S.S ${ }^{a}$ cuál es el valor a proteger en el presente caso. El valor colectivo encarnado en el bienestar de Cecilia es el patrimonio natural y cultural de la comunidad humana e integra la calidad de vida de la misma. En la medida que protegemos el patrimonio natural y cultural, protegemos y mejoramos nuestra calidad de vida. Estos son valores protegidos constitucionalmente. Una argumentación jurídica que no podemos por menos que admirar. Así como el asesinato o secuestro de una persona humana es una cuestión que no puede dejarse impune porque afecta a los valores de la colectividad, del mismo modo, no podemos dejar que Cecilia continúe en la situación de confinamiento deplorable porque va en contra de los valores colectivos que aprecia la sociedad.

Respecto al procedimiento la argumentación de la jueza es impecable: "Específicamente, el objeto del habeas corpus consiste en la protección de la libertad 
corporal ilegalmente restringida así como también la corrección en las formas o condiciones en que se cumplen las detenciones de una persona, ello conforme surge de la normativa señalada en los párrafos que anteceden. El habeas corpus está destinado a considerar la violación de un derecho o garantía sobre la libertad física de una persona por el acto de una autoridad que ha excedido el marco de su competencia o ha ido más allá de la razonabilidad que sus actos deben tener. La denuncia de habeas corpus podrá ser interpuesta por la persona que afirme encontrarse ilegítimamente detenida o que se hayan agravado sus condiciones de detención o por cualquier persona a su favor, esto es, parientes, amigos o cualquier tercero".

¿Es la acción de habeas corpus la vía correcta para salvaguardar los derechos de Cecilia? La magistrada ha imbricado una serie de normas para llegar a su conclusión afirmativa. En primer lugar, entiende que se está ante un caso de urgente protección del medio ambiente como patrimonio natural y cultural de la nación. Y lo argumenta en base a las leyes positivas. El Art. 5o del Código Procesal Penal dispone que los tribunales deberán resolver el conflicto surgido a consecuencia del hecho, de conformidad con los principios contenidos en las leyes, en procura de contribuir a restaurar la armonía social entre sus protagonistas. En causas en las que está en juego el derecho colectivo a la preservación del patrimonio natural y cultural el juez actúa para "proteger efectivamente el interés general" (Art. 32 de la ley 25.675). Es decir, la magistrada se ve en la obligación de entrar en el fondo del asunto y resolver.

La Corte Suprema de Justicia de la Nación en el conocido caso "Mendoza" (contaminación del río Matanza-Riachuelo) dijo: "La mejora o degradación del ambiente beneficia o perjudica a toda la población, porque es un bien que pertenece a la esfera social y transindividual, y de allí deriva la particular energía con que los jueces deben actuar para hacer efectivos estos mandatos constitucionales" (considerando 18).

Por otro lado, en el caso de Cecilia se dan las dos características fundamentales del instituto en cuestión: la sumariedad, que tiende a que en el procedimiento no se ventilen cuestiones de incidencia previa, y la urgencia, la que se traduce en el procedimiento previsto para la acción de habeas corpus. Ahora bien, ¿cómo aplicar un procedimiento pensado para personas a un animal? Aquí la jueza se pregunta: ¿Son los grandes simios -orangutanes, bonobos, gorilas y chimpancés- sujetos de derechos no humanos? ¿Sólo el ser humano puede ser considerado como persona en tanto sujeto de derecho? ¿El hombre es el único que posee capacidad de derecho? Considera la magistrada, como este autor, que hay que reconstruir el concepto de persona y de personalidad jurídica. 
Al hilo de estas preguntas, la magistrada afirma lo siguiente: "Resulta innegable que los grandes simios, entre los que se encuentra el chimpancé, son seres sintientes por ello son sujetos de derechos no humanos. El chimpancé no es una cosa, no es un objeto del cual se puede disponer como se dispone de un automóvil o un inmueble. Los grandes simios son sujetos de derecho con capacidad de derecho e incapaces de hecho, en tanto, se encuentra ampliamente corroborado según la prueba producida en el presente caso, que los chimpancés alcanzan la capacidad intelectiva de un niño de 4 años."

La argumentación tiene momentos brillantes. Uno de ellos es cuando a aquellos que defienden con la ley en la mano que los animales son jurídicamente cosas, les enfrenta con "Ia clara incoherencia de nuestro ordenamiento jurídico que por un lado sostiene que los animales son cosas para luego protegerlos contra el maltrato animal, legislando para ello incluso en el campo penal. Legislar sobre el maltrato animal implica la fuerte presunción de que los animales "sienten" ese maltrato y de que ese sufrimiento debe ser evitado, y en caso de producido debe ser castigado por la ley penal." Cabe señalar que en el delito de maltrato animal regulado por la Ley núm.. 14.346 (en España en los arts. 337 y 337 bis del Código Penal) el bien jurídico protegido es el derecho del animal a no ser objeto de la crueldad humana. La interpretación del fin perseguido por el legislador implica que el animal no es una cosa, no es un semoviente sino un ser vivo sintiente. La conclusión no es otra que los animales son sujetos de derecho que poseen derechos fundamentales que no deben ser vulnerados.

Otro elemento positivo de la sentencia que comentamos es que recoge y se apoya en la Declaración Universal de los Derechos Animales, elaborada en el año 1977, y que a partir del 3 de noviembre y gracias a la magistrada del Tercer Juzgado de Garantías adquiere un mayor valor. Así recoge la motivación de la sentencia que en esa Declaración se reconoce expresamente: que los grandes simios entre otras especies tienen derecho a vivir en libertad. ¿Es una jaula, aun con grandes dimensiones, el lugar adecuado? Y la respuesta negativa brota de forma

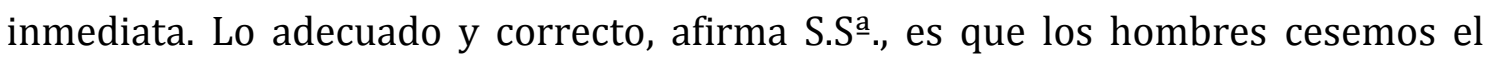
cautiverio de los animales para su exposición y entretenimiento de personas, dado que son sujetos de derechos no humanos y como tales poseen el derecho inalienable a vivir en su hábitat, a nacer en libertad y conservarla.

Y, finalmente, la última argumentación de la magistrada no puede ser más sensata y brillante. Dice: “Es la acción de habeas corpus la vía procedente? Considero que la respuesta ha de ser afirmativa. Dado que ni la regulación procesal de la provincia ni ley nacional alguna contemplan específicamente una vía procesal para evaluar la situación de animales en estado de encierro en establecimientos zoológicos o de cualquier condición de encierro en contrario a las necesidades básicas y al 
hábitat natural del animal de que se trate, considero que la acción de habeas corpus es la vía procedente ajustándose la interpretación y la decisión que recaiga a la situación específica de un animal privado de sus derechos esenciales en tanto éstos están representados por las necesidades y condiciones esenciales de la existencia del animal en cuyo favor se acciona."

¿Qué quiere decir? Que encontrándose en la obligación legal de resolver sobre el fondo del asunto, resulta que no tiene otro procedimiento más apropiado que el del habeas corpus. Y por eso lo aplica, dado que de no hacerlo, estaría incumpliendo aquella obligación.

En conclusión, la sentencia del Tercer Juzgado de Garantías de Mendoza apoya la revolución tranquila que trabaja por el reconocimiento de los animales como sujetos de derechos. Debemos felicitarnos por esta decisión que abre otra brecha en el muro del derecho decimonónico. 